\title{
FAULT ANALYSIS ON THREE PHASE SYSTEM BY AUTO RECLOSING MECHANISM
}

\author{
Vinesh Gamit ${ }^{1}$, Vivek Karode ${ }^{2}$, Karan Mistry ${ }^{3}$, Pankaj Parmar ${ }^{4}$, Ashish Chaudhari ${ }^{5}$ \\ ${ }^{I}$ Student of Electrical Engineering, CGPIT Bardoli, Gujarat, India \\ ${ }^{2}$ Student of Electrical Engineering, CGPIT Bardoli, Gujarat, India \\ ${ }^{3}$ Student of Electrical Engineering, CGPIT Bardoli, Gujarat, India \\ ${ }^{4}$ Student of Electrical Engineering, CGPIT Bardoli, Gujarat, India \\ ${ }^{5}$ Assistant professor, Electrical Engineering, CGPIT Bardoli, Gujarat, India
}

\begin{abstract}
In any electrical system, due to overvoltage or over current line--ground fault, line to line fault, line-line-line fault and line-lineline-ground faults occur. The electrical substation is supply the power to the consumers means industries or domestic can have failures due to any of the fault which can be temporary or permanent. These faults lead to damage to the power system equipment. In this work, effort has made to design an reclosing mechanism in case of permanent or temporary fault. The TimerIc-555 has been used to give the time duration of fault. Circuit breaker is used for disconnecting the line at fault instant and connecting on clearance of fault. Reclosing mechanism resets the supply line after small interruption in the event of temporary fault or it remains in tripped condition in case of permanent fault.
\end{abstract}

Keywords: Fault Analysis, Timer 555, Auto Reclosing Mechanism $* * *$

\section{INTRODUCTION}

As from the studies $70 \%$ to $90 \%$ of faults are occurred in overhead transmission line which are transient. There are many transient fault, such as damages of insulation, swinging wires and little time contact with other objects. these faults are cleared by operating the circuit breakers or can be cleared by de-energizing the line at short period for clearing the fault.

The other $30 \%$ to $10 \%$ faults are occurred in overhead line which are permanent or long duration fault. permanent or long duration fault occurred by broken wire which results one phase to ground fault or joining the two phase together which is occurred in overhead line as well as in the underground cable. these fault cleared by finding them in line and repair which results permanent trip of line.

In an electric power system, a fault is any instant which is not normal electric current or unbalanced condition of system. As we consider, a short circuit is a fault in which current bypasses the normal load and an open circuit fault occurs if a circuit is interrupted by some failure. In threephase system, a fault should carry one or more phases. In ground fault or earth fault charge flows into the earth. In power systems, many of devices detect the fault or abnormal condition and operate the circuit breaker to prevent the fault or save system from damages.

Here Auto reclosing mechanism success rates vary from one company to another, because most of faults can be successfully cleared by proper use of tripping and reclosing the line. The line is turn off when fault take place and reclose the line when fault and fault arc is removed from line. This mechanism reduced the line outage time due to fault and provide continues supply to the consumer and also maintain the system.

\section{FAULT ANALYSIS}

Faults are classified into two parts, Active and Passive Fault.

\subsection{Active Fault}

When current passing from one phase to another phase or phase to ground is known as Active fault.

This fault must be cleared as quickly as possible otherwise it's damages to the conductor or line or the equipment.

\subsection{Passive Fault}

Passive faults are stressing the system beyond it's design and long duration fault which ultimately results in active fault.

Examples are:

Overloading - When load increased it's results in voltage increased and insulation is overheating. ?

Overvoltage - Voltage is increased to it's rated voltage and stressed to the insulation.?

Under frequency - Frequency goes below to it's rated frequency it results in plant to behave incorrectly. ?

Power swings - generators outage and loss of synchronism. 


\subsection{Types of Fault on a Three Phase System}

Faults occurred on a three phase A.C. system shown in fig 1 are as follows:
A) Phase-to-earth fault
B) Phase-to-phase fault
C) Phase-to-phase-to-earth fault
D) Three phase fault
E) Three phase-to-earth fault ?

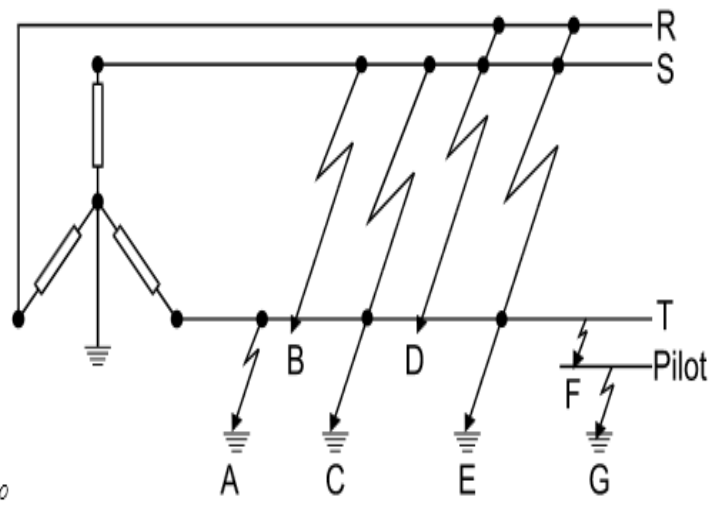

Fig- 1: Types of faults

\subsection{Transient \& Permanent Fault}

Transient faults are didn't damage the insulation of wire and there are small in time duration and after that period circuit is re-energized.

These faults are occur on outdoor equipment because the air is main medium to take place the transient fault.

Example of transient fault are insulator flashover and lightning stroke, when it happen the circuit is de-energized or open by circuit breaker and after a brief interval it will reclose.

Permanent fault as name suggest it is the permanent fault, which damage permanently to the insulation.

In this period line will permanent de-energized and repaired.

\subsection{Symmetrical \& Asymmetrical Fault}

A symmetrical fault is a balanced fault which are occurred on three phase. these three phase has same value of fault current. Magnitude of all fault current is same. These faults are same in three line or three line to ground fault.

An asymmetrical fault has a d.c. offset, transient in nature and unbalanced fault. They are occur on single line, double line or single line to ground or double line to ground.

\section{BLOCK DIAGRAM}

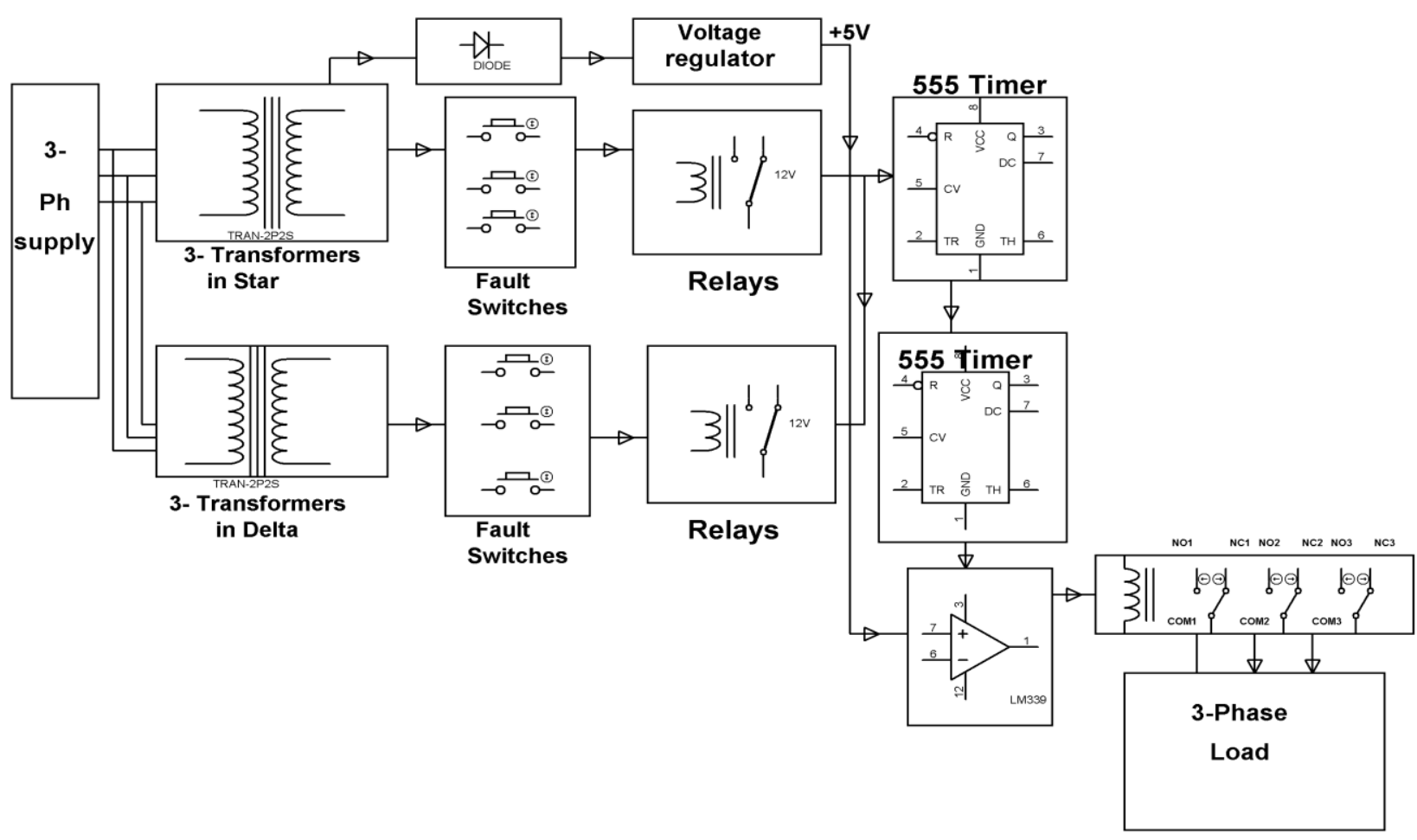

Fig-2: Block Diagram 
In this circuit six number of step down transformer are used forming the star and delta connection. Their input is 220 volt and gives output in 12 volt. This is due to low voltage testing of fault and detect the fault condition and operate circuit breaker and other device to limit the loss of service due to failure.

Fault condition is created by using of set of fault switches to Line-Line(LL), Line-Ground (LG), Three Line(3L) fault to circuit. These faults are triggered a 555Timer IC. It is operate in Monostable to reset or reclose the system after fault clearance in a short duration or temporary fault clearance and operate in Astable for long duration or permanent trip.

\section{COMPONENT OF BLOCK DIAGRAM}

\subsection{Transformer}

Transformer is device used for increase and decrease the voltages. Here step down transformers are used for step down the voltage at 12 volt from 220 volt AC.

Transformers are used at different location as well as transmission and distribution. Type of transformer are mainly two core type and shell type.

According to the supply they are classified in single phase and three phase or the different voltages. different type of connection are there which are star-star, delta-delta, stardelta, delta-star.

\subsection{Switches}

There are many types of switches are there.

\subsubsection{Toggle Switch}

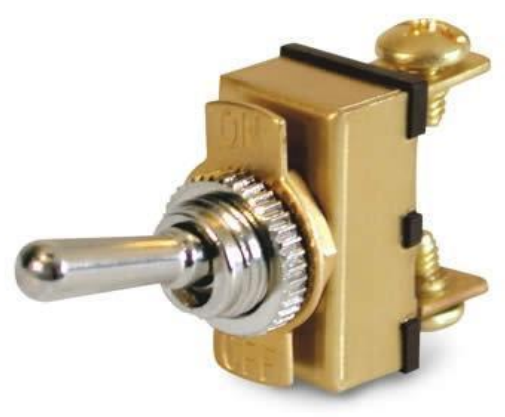

Fig-3: Toggle switch

Toggle switches are operated on lever mechanism to put in angled one of two or more position of lever. it is used in the house wiring. Most of the toggle switches are used as lever mechanism and others are used as the spring mechanism.

\subsubsection{Push Button}

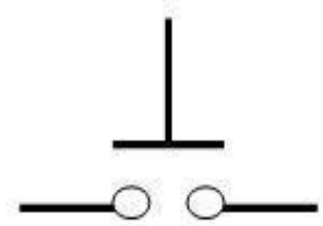

Normally Open (NO)

(i)

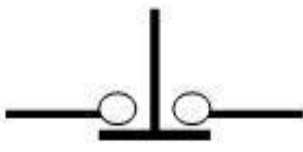

Normally Closed (NC)

(ii)
Fig-4: Operation of push button

This switch is in two position and device actuating with button press is on and released when off. This switch is used by an internal spring mechanism when it is off or unenergized position. Other switches will latch sequencly on and off when push button is pressed. Some push button remain in ON position when pressed till it's not get off or pulled back out.

\subsubsection{Selector Switch}

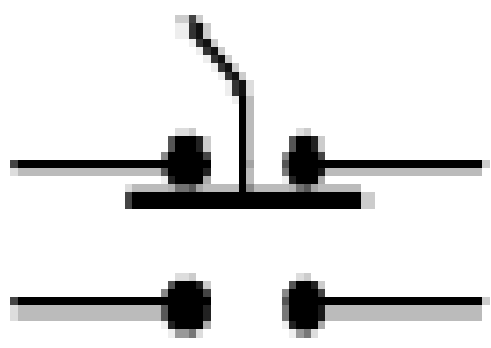

Fig-5: Selector Switch

These switches are actuating by rotation of knob or lever operation in angle of one of two or more position. It's also work as Toggle switch, remain in same position when $\mathrm{ON}$ and returning by spring mechanism.

\subsubsection{Joystick Switch}

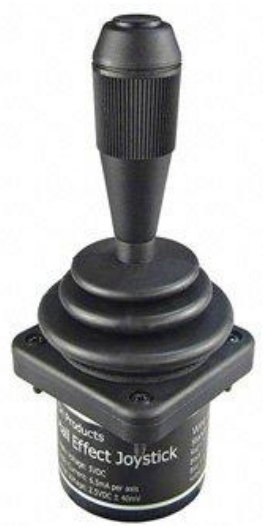

Fig-6: Joystick switch

This switch is operated by use of lever to move in more than one axis of motion or movement. 


\subsection{Relay}

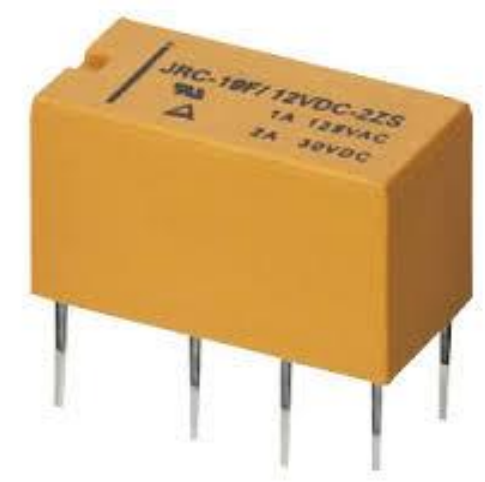

Fig-7: Relay

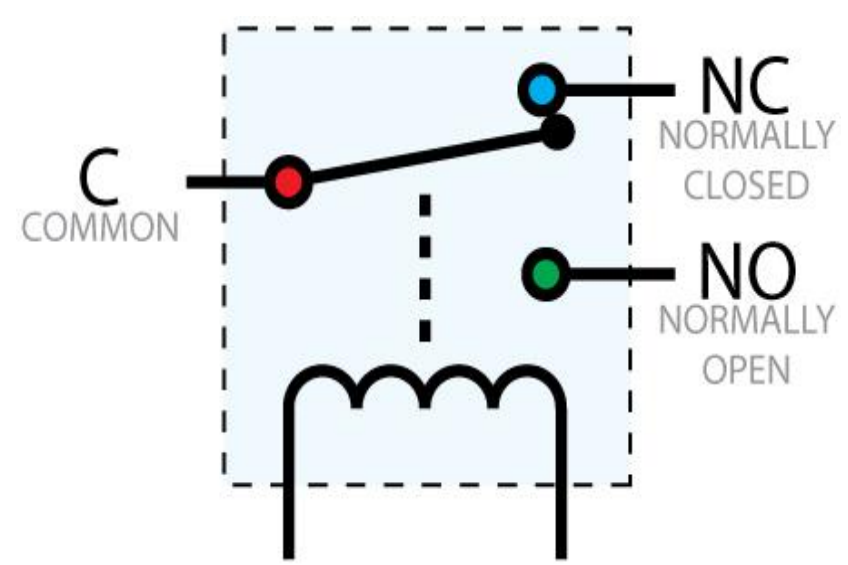

Fig-8: Relay Contact

Here figure shows the relay and relay contact. There are three terminal of the relay contact one is common for the supply and the other two or normally open and normally close.

Relay is connected in circuit as we want as normally open or normally close. When relay coil is energized by the current it results to pull the plunger or push the plunger as it's connection. by the operation of relay one signal is given to the circuit breaker and it's disconnect the circuit.

\subsection{Voltage Regulator}

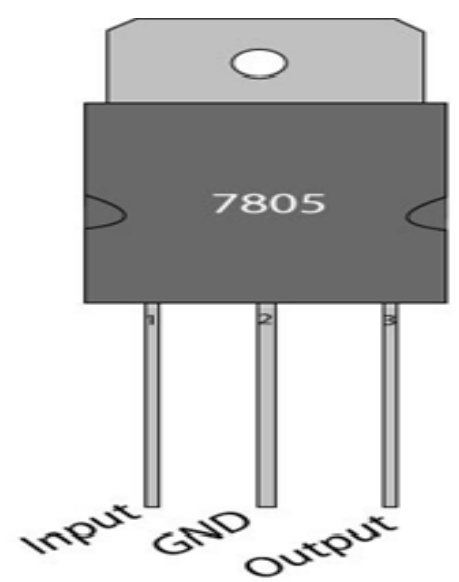

Fig-9: Voltage Regulator
Voltage regulator which is integrated circuit number is 7805. Normally $78 \mathrm{xx}$ series used for the fixed linear voltage regulated ICs. it is used because the voltage from the voltage source is not fixed it's fluctuate so for the fixed supply to the circuit voltage regulator is used.

It has 3 pin, two is input and output and the other is ground. 7805 voltage regulator gives +5 v supply.

\subsection{Timer Ic555}

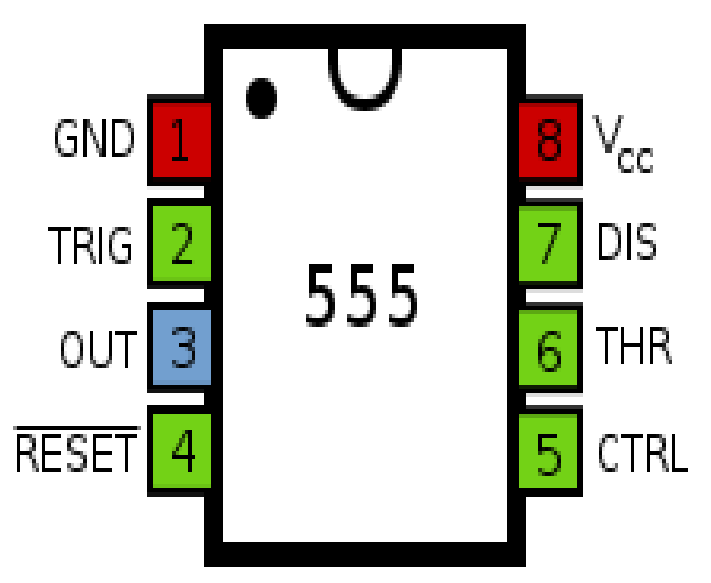

Fig-10: Timer IC555

The 555Timer IC is a integrated circuit, simple 8 pin Dual in Line package. It is used as Monostable and Astable or as Timer IC. It's supply voltage is $5 \mathrm{v}$ to $15 \mathrm{volt}$. 


\section{SIMULINK MODEL}

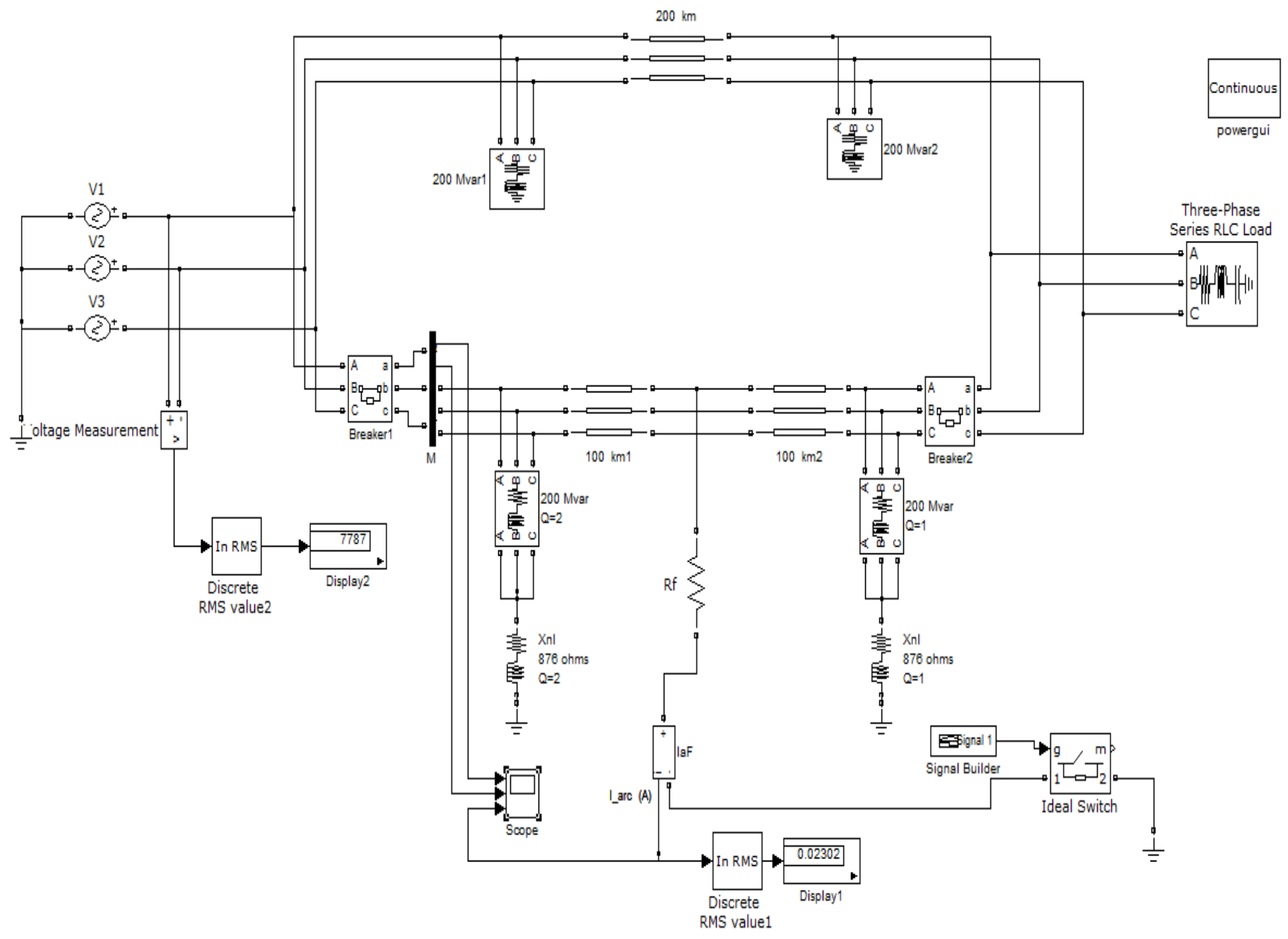

Fig-11: Simulink Model

For simulation MATLAB software is used. In this software the simulation is carried out by making the transmission line with loads. Circuit breaker is used for opening at fault instant and closing at fault clearance. Switch is used for creating the fault. simulink model shown in fig 11 .

In this model fault time is given by the Signal builder. Ideal switch is connected with signal builder when signal is given to the switch, it is going to close and fault will occur in the system and that instant circuit breaker is operate and disconnect the system from faulty part.

\section{RESULTS AND ANALYSIS}

Different voltage unbalance such as LL(Line to Line), LG(Line to Ground), 3L(Three Lines) has been observed. These faults are carried out by closing the fault switch in simulink model. These faults are taken temporary as well as permanent.

\subsection{Line to Ground Fault}
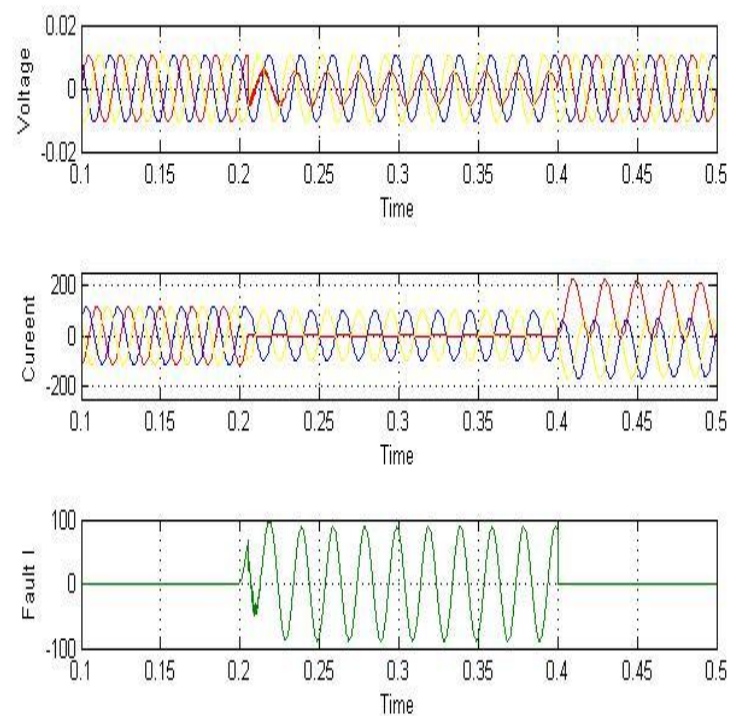

Fig-12: Temporary Line to Ground Fault 
$\mathrm{X}$-axis shows Time and Y-axis shows three system Voltage, Current and Fault current between two contact of Circuit Breaker. From the Figure 12, it is shown that fault occurs in one line at a time 0.2 second and it is cleared at 0.4 second. It is a Temporary fault which is cleared by auto reset.
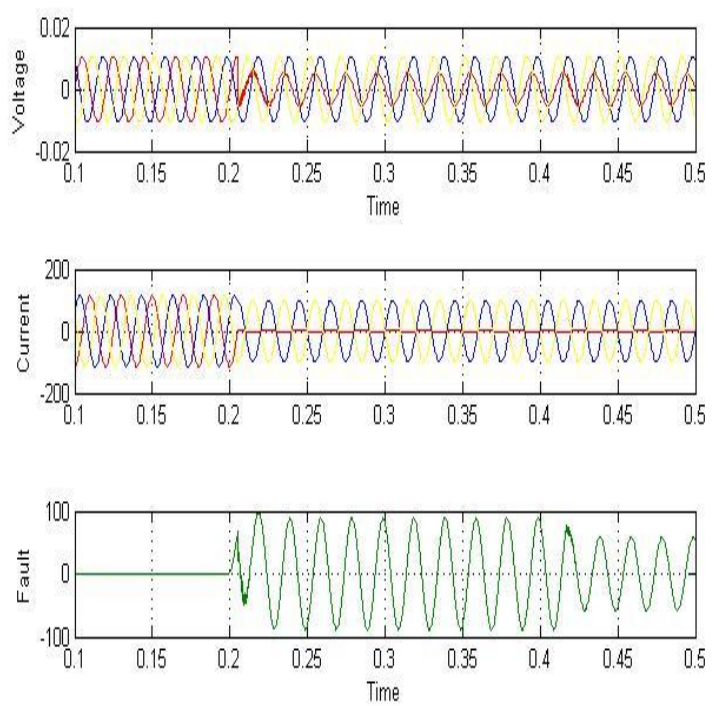

Fig-13: Permanent Line to Ground Fault

From figure 13 it's clear that the line to ground fault is permanent, it's not cleared at a time instant of 0.4 second. Hence, it's permanent fault and line will shut down.

\subsection{Line to Line Ground Fault}
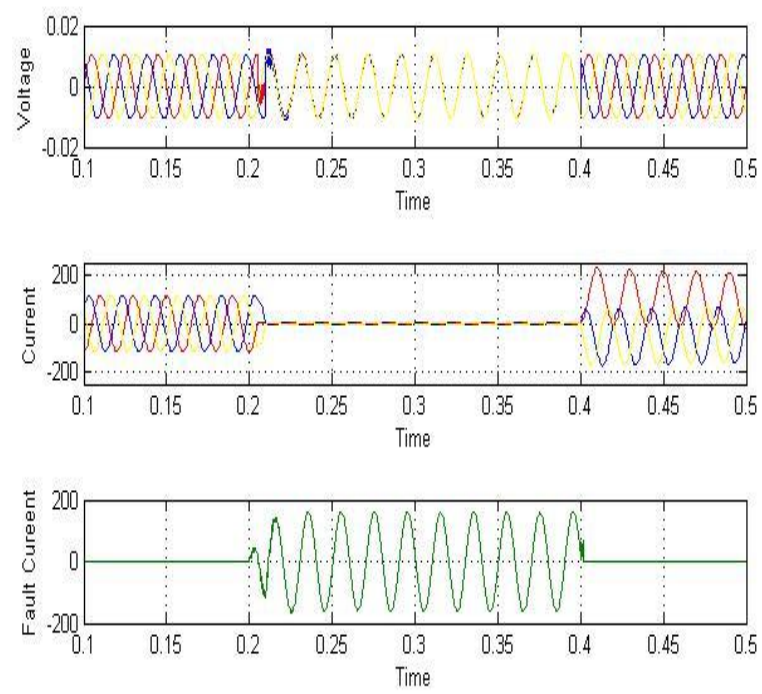

Fig-14: Temporary Line- Line-Ground Fault

In this, line-line-ground fault has been shown and from the waveform, it can be shown that its temporary.
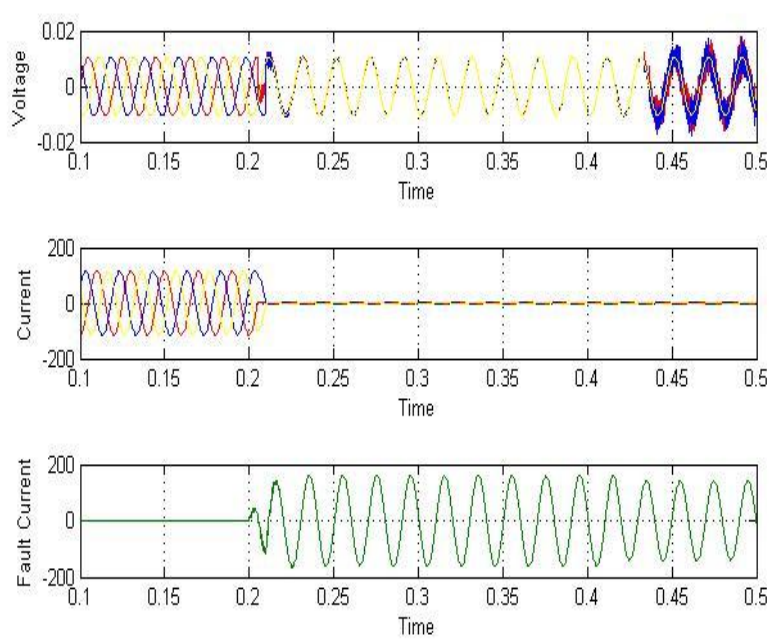

Fig-15: Permanent Line-Line-Ground fault

\subsection{Line-Line-Line-Ground Fault}
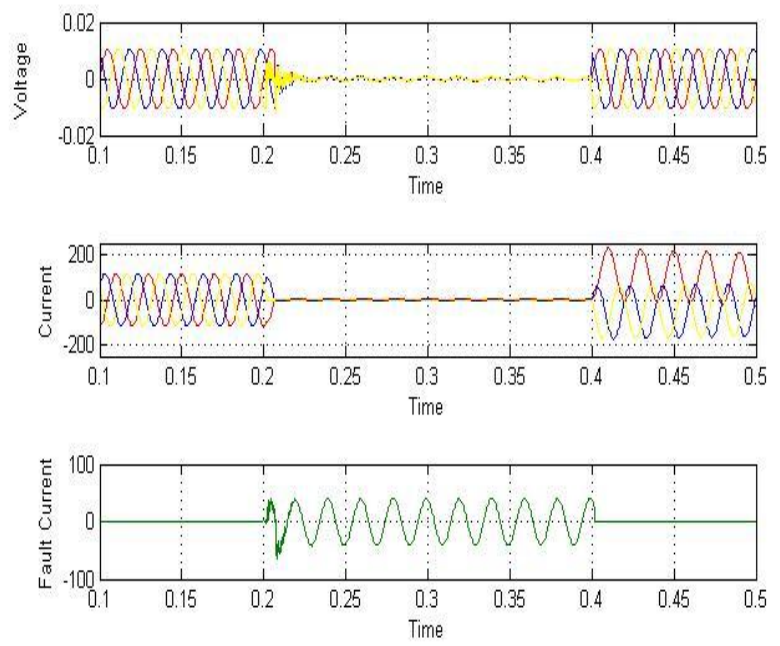

Fig-16: Temporary Line-Line-Line-Ground Fault
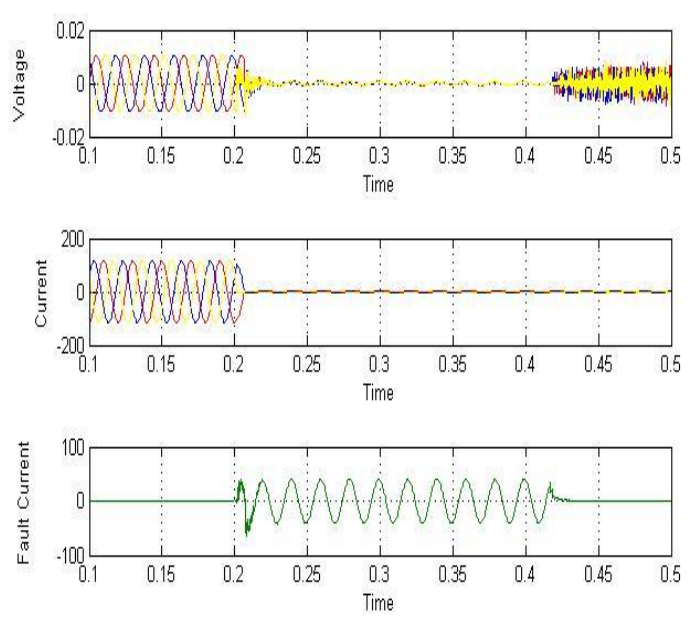

Fig-17: Permanent Line-Line-Line-Ground Fault 


\section{CONCLUSION}

Various faults have been Simulated to develop an automatic tripping mechanism for the three phase supply system while temporary fault and permanent faults occur. Here timer 555 has been used with relay for the fault analysis. Short duration fault back to the supply to the load immediately called as temporary trip while long duration shall result in permanent trip.

\section{ACKNOWLEDGEMENTS}

We would like to thank our guide for constant support and necessary guidance and also thanks to our faculties who have helped us.

\section{REFERENCES}

[1]. Sathish Bakanagari,(2013) "Three Phase Fault Analysis with Auto Reset for Temporary Fault and Trip for Permanent Fault" Int. Journal of Engineering Research and Applications vol.3,1082-1086

[2]. Akagi H., H.E. Watanabe, M. Aredes.(2007) "Instantaneous power theory and applications to power conditioning", Wiley-IEEE Press, 2007, pp. 43-105

[3]. Bollen. M.H.J. (2003) "Voltage recovery after unbalanced and balanced voltage dips in three-phase systems, IEEE Transactions on Power Delivery 18 ,13761381

[4]. Aleksandar M. Stankovic (2000) "Analysis of Asymmetrical Faults in Power Systems Using Dynamic Phasors" IEEE Transactions On Power Systems 15,10621068

[5]. Savas Koc, Zafer Aydogmus (2009) "A Matlab/gui based fault simulation tool for power system education", Mathematical and Computational Applications, Vol. 14, No. 3, pp. 207-217

[6]. Kimbark, Edward Wilson, ScD; Power System Stability; John Wiley \& Sons, Inc.,N.Y., London

[7]. HAVRAN, F.J. 1999. Fault investigation on power transmission system. ESKOM. Internaldocument: 38, 9699KELLER, P.1998. Correct fault analysis. Eskom internal document

[8]. Turan Gonen, "Electric Power Transmission System Engineering, Analysis and Design",Crc Press Taylor and Francis Group.

[9]. Paul M. Anderson, "Analysis of Faulted Power Systems", The Institute of Electrical and Electronics Engineers, Inc., 1995.

\section{BIOGRAPHIES}

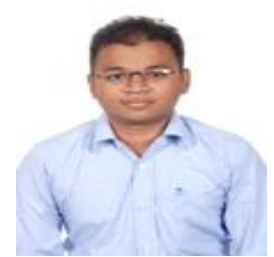

Vinesh R. Gamit is pursuing B.TECH in Electrical Engineering from CGPIT,UKA TARSADIA UNIVERSITY, Maliba Campus, Bardoli,Gujarat,India

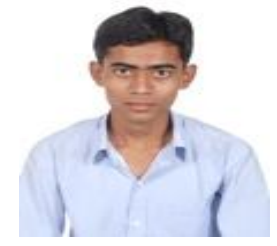

Vivek R. Karode is pursuing B.TECH in Electrical Engineering from CGPIT,UKA TARSADIA UNIVERSITY, Maliba Campus,

Bardoli,Gujarat,India

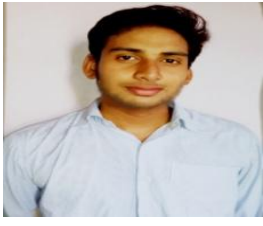

Karan M. Mistry is Pursuing B.TECH in Electrical Engineering from CGPIT, UKA TARSADIA UNIVERSITY, Maliba Campus, Bardoli,Gujarat,,India

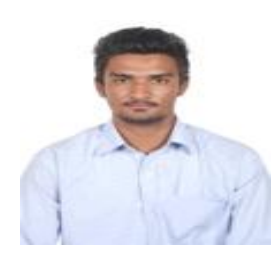

Pankaj P. Parmar is pursuing B.TECH in Electrical Engineering from CGPIT,UKA TARSADIA UNIVERSITY, Maliba Campus, Bardoli,Gujarat,India

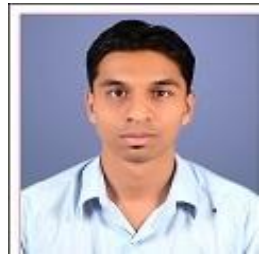

Ashish B.Chaudhari is an Assistant professor in Electrical Engineering Department of CGPIT,UKA TARSADIA UNIVERSITY, Maliba Campus,Bardoli, Gujarat,India 